\title{
Discovery of the first European parasitoid of the emerald ash borer Agrilus planipennis (Coleoptera: Buprestidae)
}

\author{
Marina J. ORLOVA-BIENKOWSKAJA ${ }^{1}$ and SERgey A. BELOKOBYLSKIJ ${ }^{2}$
}

\begin{abstract}
${ }^{1}$ A.N. Severtsov Institute of Ecology and Evolution, Russian Academy of Sciences, 33 Leninskiy Prospect, Moscow 119071, Russia; e-mail: marinaorlben@yandex.ru

${ }^{2}$ Zoological Institute, Russian Academy of Sciences, St Petersburg 199034, Russia; Museum and Institute of Zoology Polish Academy of Sciences, Wilcza 64, Warszawa 00-679, Poland; e-mail: doryctes@gmail.com
\end{abstract}

Key words. Hymenoptera, Braconidae, Spathius polonicus, Coleoptera, Buprestidae, Agrilus planipennis, parasitoid, biocontrol, emerald ash borer, European Russia, Fraxinus pennsylvanica

\begin{abstract}
The emerald ash borer, Agrilus planipennis, native to Asia is a devastating pest of ash in North America and European Russia. There are several parasitoids of A. planipennis recorded in Asia and North America, but none previously in Europe and European Russia. Eighty two specimens of the ectoparasitoid Spathius polonicus Niezabitowski (Hymenoptera: Braconidae: Doryctinae) (23 adults, 56 larvae and three pupae) were found in the remains of $A$. planipennis larvae at five localities in Moscow Province in October 2013 - May 2014. S. polonicus is rare but widely distributed and mainly a Western Palaearctic species. It seems that the level of parasitism could be relatively high: in nature, more than $50 \%$ of the last instar larvae of $A$. planipennis examined were killed by $S$. polonicus. We collected 24 live last instar larvae and prepupae and the remains of 30 last instar larvae of $A$. planipennis previously parasitized by S. polonicus. S. polonicus may be suitable for the biocontrol of A. planipennis both in Europe and North America, because it is a native of the temperate climate zone. The potential of this parasitoid for biological control needs special investigation.
\end{abstract}

\section{INTRODUCTION}

The emerald ash borer (EAB), Agrilus planipennis Fairmaire, 1888 (Coleoptera: Buprestidae), is native to East Asia (Wei et al., 2007). About ten years ago it was recorded in North America (Haack et al., 2002) and Russia (Moscow) (Mozolevskaya \& Izhevskiy, 2007). Since then it has become a major invasive pest of ash, killing nearly all ash trees in areas it has colonized (Knight et al., 2013; Orlova-Bienkowskaja, 2014). The range of $A$. planipennis is expanding quickly: the pest is currently recorded in 23 states of USA, two provinces of Canada (Emerald ash borer website, 2014) and 11 provinces of European Russia (Orlova-Bienkowskaja, 2013). Almost all ash trees in Moscow and its vicinity have been killed by A. planipennis (Straw et al., 2013). There is no doubt that this pest will spread to other European countries (Baranchikov et al., 2008). The possibilities for the biological control of $A$. planipennis are being intensively studied (Bauer et al., 2008; Belokobylskij et al., 2012). So cases of parasitized $A$. planipennis are of special interest. Several parasitoids attacking A. planipennis are recorded in Asia and North America, but none in European Russia (Baranchikov et al., 2008; Belokobylskij et al., 2012; Taylor et al., 2012).

\section{RESULTS}

Between October 2013 and May 2014 in Moscow Province we collected 54 last instar larvae of $A$. planipennis from under the bark of Fraxinus pennsylvanica of which 30 had been killed by the ectoparasitoid Spathius polonicus Niezabitowski, 1910 (Hymenoptera: Braconidae: Doryctinae). Eighty two specimens of $S$. polonicus were found in the remains of larvae of $A$. planipennis: 23 adults, 56 larvae and three pupae (Table 1, Figs 1-3). In addition, we examined one female of $S$. polonicus reared from larvae collected from ash at Pushkino (Moscow Province) and five reared from material from Abies sibirica in Kemerovo Province
(5 females, Kemerovo Province, Tisul' District, Makarovskoe Forestry, from dry Abies sibirica, 30.v.2011, M. Klyukin leg.).

\section{DISCUSSION}

S. polonicus is rare, but a widely distributed Western Palaearctic species. It occurs in Spain, Netherlands, Switzerland, Italy, Poland, Czech Republic, Slovakia, Serbia, Belarus, Ukraine, Russia (south-east of the European part), Armenia, Azerbaijan, Turkmenistan, Uzbekistan, Tadjikistan, Iran (Belokobylskij, 2003; Yu et al., 2012) and Belgium (Belgian Species List, 2014). It was not recorded in Moscow Province or the center of European Russia and the only previously known locality in European Russia is in its south-eastern part, Volgograd Province (Belokobylskij, 1989). We found S. polonicus at six localities north of Moscow. The distance between the two most remote localities is about $50 \mathrm{~km}$. So $S$. polonicus is rather widely distributed in the region of this outbreak of $A$. planipennis. Finding $S$. polonicus in Kemerovo Province is the first record of this species in Siberia.

S. polonicus is an ectoparasitoid of mainly buprestid larvae: Agrilus suvorovi Obenberger, 1935 (Kenis \& Hilszczanski, 2007), A. viridis Linnaeus, 1758 (on Populus nigra), A. constantini Obenberger, 1927, Anthaxia sp., Coraebus florentinus (Herbst, 1801), Melanophila picta (Pallas, 1773), Melanophila picta decastigma (Fabricius, 1787), Ovalisia mirifica (Mulsant, 1855), Cratomerus sp., Sphenoptera kaznakovi Jakovlev, 1899 and $S$. davatchii Descarpentries, 1960, and exceptionally also Scolytus sp. (Curculionidae: Scolytinae) (Belokobylskij, 2003; Yu et al., 2012).

Several species of parasitoids are recorded attacking A. planipennis in Asia and North America (Belokobylskij et al., 2012). There are five species of the genus Spathius among them: $S$. simillimus Ashmead, 1893, S. floridanus Ashmead, 1893 and S. laflammei Provancher, 1880 are native to America (Taylor et al., 2012), and S. agrili Yang, 2005 and S. galinae Belokobylskij 


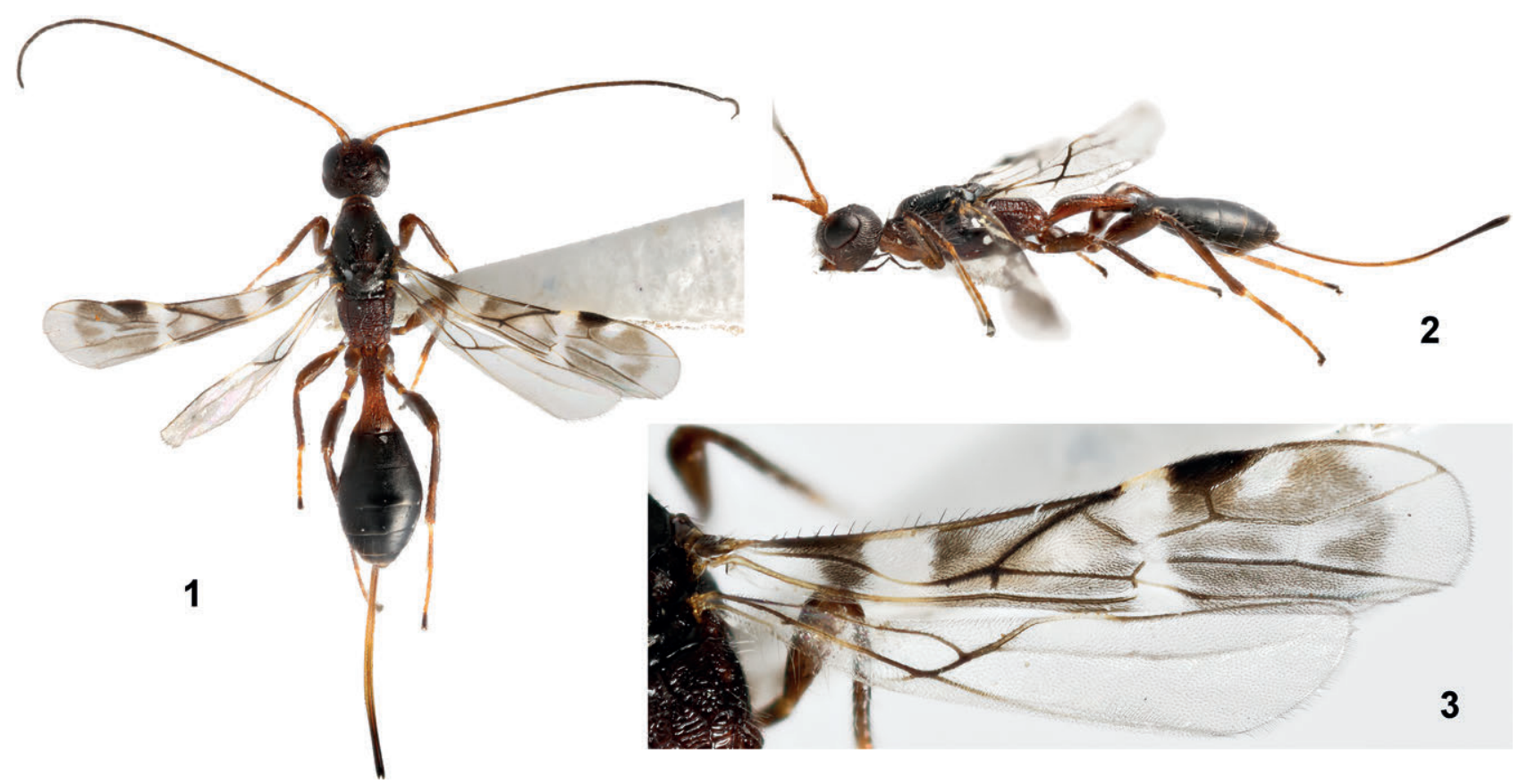

Figs 1-3. Spathius polonicus (Niezabitowski). 1 - dorsal view; 2 - lateral view; 3 - wings.

et Strazanac, 2012 are native to Asia (Yang et al., 2005; Belokobylskij et al., 2012).

Three species of parasitoids were introduced from China into the United States for classical biocontrol of emerald ash borer: Spathius agrili Yang, 2005, Tetrastichus planipennisi Yang, 2006 and Oobius agrili Zhang et Huang, 2005 (Bauer et al., 2008). Although these parasitoids have established stable populations at several U.S. locations, parasitism rates of emerald ash borer by these parasitoids from China are considerably lower in newly introduced regions than those reported in China (Duan et al., 2012). Recently a new species attacking A. planipennis, Spathius galinae Belokobylskij et Strazanac, was described (Belokobylskij et al., 2012). It is also proposed that it could be used as biological control agent.

\section{CONCLUSIONS}

S. polonicus is the first parasitoid of $A$. planipennis to be recorded in Europe. It is possible that the level of parasitism could be rather high because more than $50 \%$ of the last instar larvae of $A$. planipennis examined were parasitized. S. polonicus may be suitable for biocontrol of A. planipennis both in Europe and
North America, because it is a native of the temperate climate zone. The potential of this parasitoid for biological control needs to be investigated.

ACKNOWLEDGEMENTS. The authors are grateful to K.V. Makarov (Moscow State Pedagogical University) for preparing the photographs. This study was supported by a grant to the second author from the Russian Foundation for Basic Research (grant No. 13-04-00026).

\section{REFERENCES}

Baranchikov Y.N., Mozolevskaya E.G., Yurchenko G.I. \& KENIS M. 2008: Occurrence of the emerald ash borer (Agrilus planipennis) in Russia and its potential impact on European forestry. - EPPO Bull. 38: 233-238.

Bauer L.S., Liu H., Miller D. \& Gould J. 2008: Developing a classical biological control program for Agrilus planipennis (Coleoptera: Buprestidae), an invasive ash pest in North America. - Newsl. Mich. Entomol. Soc. 53(3-4): 38-39.

Belgian Species List 2014: Spathius polonicus Niezabitowski, 1910. http://www.species.be/en/8753. Accessed 29 March 2014.

TABLE 1. Specimens of $S$. polonicus from EAB larvae collected from under the bark of $F$. pennsylvanica in Moscow Province.

\begin{tabular}{|c|c|c|c|c|}
\hline Locality & Date of collection & $\begin{array}{l}\text { Number of specimens } \\
\text { of S. polonicus collected }\end{array}$ & $\begin{array}{c}\text { Number of EAB last } \\
\text { instar larvae killed by } S . \\
\text { polonicus }\end{array}$ & $\begin{array}{c}\text { Number of live EAB } \\
\text { last instar larvae and } \\
\text { prepupae }\end{array}$ \\
\hline \multirow{2}{*}{$\begin{array}{l}\text { Zelenograd, 11 th district, } \\
56.00 \mathrm{~N}, 37.18 \mathrm{E}\end{array}$} & 1.-2.x.2013 & 12 larvae, 1 pupa & 2 & 8 \\
\hline & 29.x.2013 & 4 larvae, 1 pupa & 1 & 1 \\
\hline \multirow{2}{*}{$\begin{array}{l}\text { Zelenograd, 16th district, } \\
55.97 \mathrm{~N}, 37.16 \mathrm{E}\end{array}$} & 30.x.2013 & 20 larvae & 3 & 4 \\
\hline & 11.iii.2014 & 9 adults & 1 & 2 \\
\hline \multirow[t]{2}{*}{$\begin{array}{l}\text { Zelenograd, Georgievsky prospect, } \\
55.98 \mathrm{~N}, 37.21 \mathrm{E}\end{array}$} & 4.v. 2014 & 2 larvae, 1 pupa & 2 & 1 \\
\hline & 9.i.2014 & 5 larvae & 1 & 4 \\
\hline \multirow[t]{2}{*}{ Planernaya, $55.92 \mathrm{~N}, 37.38 \mathrm{E}$} & 10.iii.2014 & 1 adult, 7 larvae & 2 & 3 \\
\hline & 28.iv. 2014 & 10 adults & 12 & 0 \\
\hline Povarovka, $56.07 \mathrm{~N}, 37.07 \mathrm{E}$ & 2.v.2014 & 3 adults, 6 larvae & 6 & 1 \\
\hline Total number & - & 23 adults, 3 pupae, 56 larva & 30 & 24 \\
\hline
\end{tabular}


BelokobylskiJ S.A. 1989: The Palaearctic species of braconide wasps of the genus Spathius Nees: S. labdacus, $S$. urios and $S$. leucippus species group (Hymenoptera, Braconidae, Doryctinae). - Proc. Zool. Inst. USSR Acad. Sci. 188: 39-57 [in Russian].

Belokobylskij S.A. 2003: The species of the genus Spathius Nees, 1818 (Hymenoptera: Braconidae: Doryctinae) not included in the monograph by Nixon (1943). - Ann. Zool. 53: $347-488$.

Belokobylskij S.A., Yurchenko G.I., Strazanac J.S., ZaldivarRiveron A. \& Mastro V. 2012: A new emerald ash borer (Coleoptera: Buprestidae) parasitoid species of Spathius Nees (Hymenoptera: Braconidae: Doryctinae) from the Russian Far East and South Korea. - Ann. Entomol. Soc. Am. 105: 165-178.

Duan J.J., Yurchenko G.I. \& Fuester R. 2012: Occurrence of emerald ash borer (Coleoptera: Buprestidae) and biotic factors affecting its immature stages in the Russian Far East. - Environ. Entomol. 41: 245-254.

EMERald Ash Borer Website 2014: http://www.emeraldashborer. info. Accessed 29 March 2014.

Haack R.A., Jendak E., Liu H., Marchant K.R., Petrice T.R., Poland T.M. \& YE H. 2002: The emerald ash borer: a new exotic pest in North America. - Newsl. Mich. Entomol. Soc. 47: $1-5$.

Kenis M. \& Hilszczanski J. 2007: Natural enemies of Cerambycidae and Buprestidae infesting living trees. In Lieutier F., Day K.R., Battisti A., Grégoire J.-C. \& Evans H.F. (eds): Bark and Wood Boring Insects in Living Trees in Europe, a Synthesis. Springer, Dordrecht, pp. 475-498.

KNIGHT K.S., BRown J.P. \& Long R.P. 2013: Factors affecting the survival of ash (Fraxinus spp.) trees infested by emerald ash borer (Agrilus planipennis). — Biol. Invasions 15: 371-383.
Mozolevsskaya E.G. \& Izhevskiy S.S. 2007: The foci of the ash buprestid in Moscow region. - Zashch. Karant. Rast. 5: 2829 [in Russian].

Orlova-BienkowsKaja M.J. 2013: Dramatic expansion of the range of the invasive ash pest, buprestid beetle Agrilus planipennis Fairmaire, 1888 (Coleoptera, Buprestidae) in European Russia. - Entomol. Rev. 93: 1121-1128.

ORLOVA-BIENKOWSKAJA M.J. 2014: Ashes in Europe are in danger: the invasive range of Agrilus planipennis in European Russia is expanding. - Biol. Invasions 16: 1345-1349.

StraW N.A., Williams D.T., Kulinich O. \& Gninenko Y.I. 2013: Distribution, impact and rate of spread of emerald ash borer Agrilus planipennis (Coleoptera: Buprestidae) in the Moscow region of Russia. - Forestry 86: 515-522.

Taylor P.B., Duan J.J., Fuester R.W., Hoddle M. \& Van DriESCHE R. 2012: Parasitoid guilds of Agrilus woodborers (Coleoptera: Buprestidae): their diversity and potential for use in biological control. - Psyche doi: 10.1155/2012/813929

Wei X., Wu Y., Reardon R., Sun T.H., Lu M. \& Sun J.H. 2007: Biology and damage traits of emerald ash borer (Agrilus planipennis Fairmaire) in China. - Insect Sci. 14: 367-373.

Yang Z.Q., Achterberg C.V., Chol W.Y., Strazanac J.S. \& MARsh P.M. 2005: First recorded parasitoid from China of Agrilus planipennis: a new species of Spathius (Hymenoptera: Braconidae: Doryctinae). - Ann. Entomol. Soc. Am. 98: 636642.

Yu D.S., van Achterberg C. \& Horstman K. 2012: Taxapad 2012, Ichneumonoidea 2011. Database on flash-drive. Ottawa, Ontario, Canada.

Received April 28, 2014; revised and accepted June 2, 2014 Prepublished online August 13, 2014 